\title{
1324 Prison Suicides in 10 Countries in South America: Incidence, relative Risks, and ecological Factors
}

Francesco Domenico Fritz ${ }^{1,2}$, Seena Fazel ${ }^{3}$, Andrés Benavides Salcedo ${ }^{4}$, Paulette Henry $^{5}$, Guillermo Rivera Arroyo ${ }^{6}$, Julio Torales ${ }^{7}$, Natalia Trujillo Orrego ${ }^{8}$, Freddy Vasquez $^{9}$, Adrian P Mundt $^{10,11^{*}}$

${ }^{1}$ Department of Psychiatry and Psychotherapy, Charité Universitätsmedizin Berlin, Campus Mitte, Berlin, Germany

${ }^{2}$ Department of Psychiatry, Hospital Clínico, Universidad de Chile, Santiago, Chile

${ }^{3}$ Department of Psychiatry, University of Oxford, Oxford, UK

${ }^{4}$ Ministry of Public Health, Quito, Ecuador

${ }^{5}$ Department of Sociology, University of Guyana, Georgetown, Guyana

${ }^{6}$ Department of of Psychology, Private University of Santa Cruz de la Sierra, Santa Cruz de la Sierra, Bolivia

${ }^{7}$ Department of of Psychiatry, School of Medical Sciences, National University of Asunción, San Lorenzo, Paraguay

${ }^{8}$ Mental Health Research Group, National Faculty of Public Health, University of Antioquia, Medellin, Colombia

${ }^{9}$ Suicide Prevention Program, National Institute for Mental Health, Lima, Peru

${ }^{10}$ Medical Faculty, Universidad Diego Portales, Santiago, Chile

${ }^{11}$ Medical Faculty, Universidad San Sebastián, Puerto Montt, Chile

\section{* Correspondence:}

Adrian P. Mundt,

adrian.mundt@mail.udp.cl

DOI: https://doi.org/10.1007/s00127-020-01871-3

Keywords: suicide $\cdot$ prison $\cdot$ incidence $\cdot$ overcrowding $\cdot$ south america 


\begin{abstract}
Purpose

Although suicide rates of prison populations and incidence factors have been reported for high-income countries, data from low- and middle-income regions are lacking. The purpose of the study was to estimate suicide rates among prison populations in South America, to examine prison-related factors, and to compare suicide rates between prison and general populations.
\end{abstract}

\title{
Methods
}

In this observational study, we collected the numbers of suicides in prison, rates of prison occupancy, and incarceration rates from primary sources in South America between 2000 and 2017. We compared suicide rates among prisoners with incidence rates in the general populations by calculating incidence rate ratios. We assessed the effect of gender, year, incarceration rates and occupancy on suicide rates in the prison populations using regression analyses.

\section{Results}

There were 1324 suicides reported during 4437591 person-years of imprisonment between 2000 and 2017 in 10 South American countries. The mean suicide rate was 40 (95\% CI: 16 to 65) per 100000 person years for male and female genders combined. The pooled incidence rate ratio of suicide between prison and general populations was 3.9 ( $95 \%$ CI: 3.1 to 5.1) for both genders combined, 2.4 (95\% CI: 1.9 to 3.1) for men and a higher ratio in women (13.5, $95 \%$ CI: 6.9 to 26.9$)$. High occupancies of prisons were associated with lower incidence of suicide $(\beta=-58,95 \% \mathrm{CI}=$ -108.5 to -7.1$)$.

\section{Conclusions}

Suicides during imprisonment in South America are an important public health problem. Suicide prevention strategies need to target prison populations. 


\section{Introduction}

Suicides in prisons are a public health problem in many countries, and, where studied, suicide rates among prisoners are consistently higher than those in the general population [1]. The rate of suicide among prisoners was estimated to be on average 7 times higher than the rate in the general population in Europe, where suicides account for $36 \%$ of all deaths in prisons [2]. Almost all research to date on suicides in custody has been conducted in European and other English-speaking high-income countries, and information from low- and middle-income regions is scarce. To our knowledge, there are two studies from middle-income countries, one from one province in Argentina during 20002002 [3], and another from South Africa in 2015 [4], which both reported higher rates than the general population.

Health outcomes of prisoners in low and middle-income countries are important for public health for a number of reasons: conditions are typically harsh; prison services lack basic infrastructure; correctional staff often do not control the internal organization of prison wings; overcrowding is common; court procedures are slow leading to high rates of remand prisoners; access to timely and adequate health services is mostly unavailable; purposeful activities are often lacking and human rights violations have been reported [4-8]. At the individual level, high rates of mental illnesses among prisoners have been reported worldwide both in high income countries $[9,10]$ and in low- and middle-income countries [4,7,11-14]. Mental illnesses, substance use problems and repetitive self-harm have been identified as risk factors for prison suicide [9,15-17]. In high-income settings, unmet mental health treatment needs, such as medication and psychological treatments, are common in prison populations [18]. In Central and South America, systematic research is lacking, however, the availability of mental health professionals and treatments in prisons is more scarce than in high income countries [5]. In South America, prison populations and rates of incarceration have increased over the past two decades [19]. The total prison population in South America increased from around half a million in 2002 to 1.2 million in 2018 [20]. Available prison accommodation has increased slower than the incarceration rates, so occupancy rates have increased, and overcrowding is common.

In this study we assessed rates and trends of suicides among prisoners in South America and compared prison suicide rates with country- and age-matched incidence rates in the general population. We then tested associations between suicide rates among prisoners in South America and possible individual- and prison-level risk factors. 


\section{Methods}

\section{Study design and data sources}

A research network comprising 10 South American countries was built to collect data on prison populations and suicides in correctional facilities. We aimed to include 12 South American countries (Argentina, Bolivia, Brazil, Chile, Colombia, Ecuador, Guyana, Peru, Paraguay, Suriname, Uruguay, and Venezuela) in the study. Possible collaborators in each of the 12 South American countries were contacted. We corresponded with authors of indexed publications in the field of mental health and health in correctional settings, members of mental and public health research teams, institutional representatives and personal contacts. Researchers, who were unable to participate in the network or provide data, were asked to refer to colleagues in their country. This approach has been previously used to study indicators of institutionalization in South America [19] and in Europe [21,22]. We retrieved demographic data, criminological characteristics and the number of all completed suicides among the prison population in each country from their respective local prison administrations (Supplementary Table 1). We included all available data on the incidence of suicide in prison populations from the year 2000 onwards to the year 2017. Earlier data were unavailable for most countries included in the study and longer time series would have increased the risk for inconsistencies in definitions and data collection methods within the countries. We excluded populations in forensic psychiatric hospitals, juvenile offender institutions and serving partial sentences such as nocturnal or intermittent imprisonment. The authors assert that all procedures contributing to this work comply with the Helsinki Declaration of 1975, as revised in 1989.

\section{Variables possibly related to prison suicides}

Based on research from high-income countries [1,2,15,23,24], we tested the following variables that were widely available across countries for possible associations with prison suicide rates: (1) the rates of prison occupancy; (2) rates of incarceration; (3) suicide rates in the general population; and (4) gender and (5) year. Occupancy rates were calculated using annualized averages of prison populations divided by the housing capacity of the prison system for each available year. Rates of incarceration were calculated per 100000 population using annualized averages of prison populations and national populations. Suicides in the general population were retrieved from the World Health Organization (WHO) Mortality Database for male and female gender separately and combined (ICD-10 codes X6084) per 100000 general population aged 25 to 54 years. The age was matched to this range as about $80 \%$ of the adult prison population of prison administrations in high income countries falls within this range, while this is the case for only about $45 \%$ of the general population [25,26]. General population counts of people aged 25 to 54 were retrieved from the United Nations (UN). When data were not available from the UN, general population estimates were retrieved 
from the World Bank (Supplementary Table 1). Time trends were calculated based on yearly counts for each country for all available years and for all countries together between 2014-2016.

\section{Statistical Methods}

We calculated annual rates of suicide per 100000 prisoners for male and female genders combined and each gender separately using the number of annual suicide deaths and the annual prison populations for each available year. When prison services did not possess continuous registries of suicides, data were used for all available years between the year 2000 and 2017 in each country. Annual prison populations were typically based on mid-year censuses. Countries with five or more suicide events in prisons were included, since a smaller number of suicide events would not allow for reasonably accurate estimates of rate ratios in individual countries. We calculated a mean suicide rate for each country and the $95 \%$ confidence intervals $(\mathrm{CI})$ of the mean for male and female gender combined and separately for each gender. This was done by adding suicide events and prison populations of all countries between 2014 and 2016, the timeframe, for which data were available across all countries.

We calculated incidence rate ratios (IRR) between suicides in the prison population and suicides in the general population with their $95 \% \mathrm{CI}$ for male and female genders combined and for each gender separately. Incidence rate ratios are risk estimates that we calculated using the absolute total number of prison suicides and the total prison populations over the range of available years, and the absolute total number of suicides in the age-matched general population and the total general populations for the same range of years. We then calculated the weighted means for male and female genders together and for each gender separately using the IRR of each country as follows:

The weight of each country was determined by subtracting the difference between upper and lower confidence interval from the value 100 in order to assign a greater weight to IRR estimates with narrower, i.e. more accurate confidence intervals.

Meta-regression analyses were used to assess possible associations between prison suicide rates as dependent variable and gender, rates of occupancy, rates of incarceration, and rates of suicide in the general population as independent variables. Where available, rates of occupancy were obtained from national prison administrations for each year. Where unavailable, they were calculated as the ratio of prison population and housing spaces for each year. Rates of incarceration were calculated for each year as the ratio between the prison population and the general population. When data were available for each gender, meta-regression analyses were separately conducted for each gender. Metaregression analysis was used to assess time trends for all countries together using the years, for which all countries had 5 
data registries (2014-2016). Linear regression was used to assess differences of Incidence Rate Ratios between male and female prison populations, as well as time trends of suicides in prison populations for each country. P-values $<.05$ were considered statistically significant.

SPSS version 24.0 (IBM Corporation, 2016) was used to calculate rates of suicide and to assess time trends in the individual countries. STATA version 15.1 (StataCorp LLC, 2017) was used to conduct the random effects metaanalyses and meta-regression analyses.

\section{Data Appraisal}

We assessed the obtained data on prison suicide for completeness and varying definitions of suicide (Table 3). This approach has previously been used to explore varying methods of suicide data collection in prison administrations [1]. We then calculated pooled estimates of prison suicide rates stratified by categories of definitions and completeness.

\section{Results}

We retrieved data from 10 South American countries. In 8 countries (Brazil, Chile, Colombia, Ecuador, Guyana, Paraguay, Peru, and Uruguay), we obtained data covering the national prison population. In Argentina, we retrieved data for the federal justice system (Servicio Penitenciario Federal), comprising about 15\% of the national prison population. In Bolivia, we obtained data from a single maximum-security penal institution: Centro de Rehabilitación Santa Cruz Palmasola, which is Bolivia's largest facility and houses $38 \%$ of the national prison population. The availability of data ranged from 3 years in Brazil to 17 years in Chile (Table 1). The availability of data was on average 10 years. Guyana had the smallest prison population with an annual average of 1856 people, while Brazil had the largest with an annual average of 645124 people (607 106 men, 38017 women). The prison population of all 10 countries added to an annual average of 818126 people. Rates of incarceration increased in all countries over 2000 2017. Bolivia had the lowest incarceration rate with an average of 102 prisoners per 100000 population, while the highest was reported for Brazil with an average of 332 prisoners per 100000 population. The average rate of incarceration was 214 prisoners per 100000 population in the South American region. Overcrowding was reported for all countries except for the federal prisons in Argentina. The mean occupancy rate was $190 \%$, ranging from $92 \%$ in Argentina to $214 \%$ in Peru (Supplementary Table 2).

We collected information on the incidence of 1324 suicides during 4437591 person-years of imprisonment in 10 South American countries between the years 2000 and 2017. Information on gender was available for 1307 suicides, 
of which 1223 (94\%) occurred in men and $84(6 \%)$ in women. Uruguay, Argentina, and Ecuador provided specific information for transgender people. None of the suicide cases was attributed to a transgender individual in any of those countries. In Argentina, Brazil, Chile, Guyana, Paraguay and Uruguay total death counts and the proportion of suicides among all causes of death in prison were available (Supplementary Table 3). Suicide incidence rates per 100000 person years of imprisonment ranged from 8 (95\% CI: 5 to 11) in Peru to 441 (95\% CI: 388 to 492) in Bolivia (Supplementary Figures 1 and 2). Bolivia was excluded from further analyses as outlier because suicide rates were more than seven times higher than the average of the other countries and was based on a selected population of high-risk prisoners. After the exclusion of Bolivia, suicide rates per 100000 person years ranged from 8 (95\% CI: 5 to 11$)$ in Peru to 86 (95\% CI: 67 to 105) in Argentina (Table 1). Suicide rates in men ranged from 7 (95\% CI: 5 to 10) in Peru to 85 (95\% CI: 64 to 106) per 100000 person years in Uruguay (Supplementary Table 4). In women, suicide rates ranged from 14 (95\% CI: 4 to 24$)$ in Colombia to 162 (95\% CI: 50 to 274) per 100000 person years in Uruguay (Supplementary Table 5). The mean suicide rate between all countries during 2014 to 2016 was 40 (95\% CI: 16 to 65 ) per 100000 person years for both genders combined. When aggregating data of all available years in each country, the mean rate of suicides across South America was 36 (95\% CI: 27 to 45) for male and 59 (95\% CI: 20 to 99) per 100000 person years for female prisoners.

Table 1 Numbers and rates of suicide in prisoners compared with general populations in 10 South American countries between 2000 and 2017

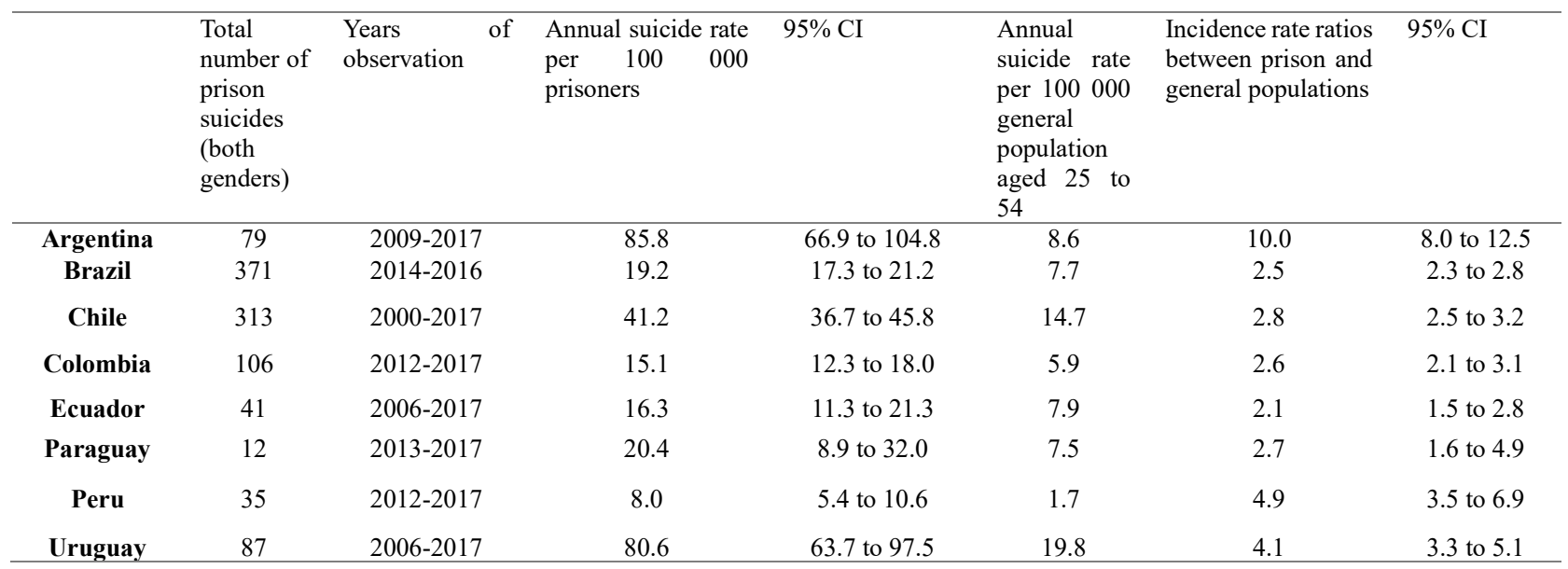


When comparing suicide rates to the general populations, rate ratios for both genders combined ranged from 2.1 (95\% CI: 1.5 to 2.8 ) in Ecuador to 10.0 (95\% CI: 8.0 to 12.5) in Argentina (Figure 1). When we pooled these rate ratios calculating a weighted mean for the whole region, we found a rate ratio of 3.9 ( $95 \%$ CI: 3.1 to 5.1 ). For male prisoners we found a pooled ratio of 2.4 ( $95 \% \mathrm{CI} 1.9$ to 3.2), with rate ratios ranging from 1.4 (95\% CI .7 to 2.7) in Paraguay to 6.1 in Argentina (95\% CI 4.8 to 7.7). In female prisoners we found a pooled ratio of 13.5 (95\%CI 6.9 to 26.9), with rate ratios ranging from 4.7 (95\% CI: 2.7 to 8.1 ) in Chile to 32.1 (95\% CI: 16.0 to 64.2) in Argentina. Linear regression showed significantly higher rate ratios in female prisoners when compared to male prisoners $(\beta=11.195 \% \mathrm{CI}=2.8$ to $19.4, \mathrm{p}=.013, \mathrm{n}=15)$.

Fig. 1 Incidence rate ratios of suicide in 10 South American countries (2000-2017) between prisoner and general populations in men (a) and women (b) of 10 South American countries (2000-2017).
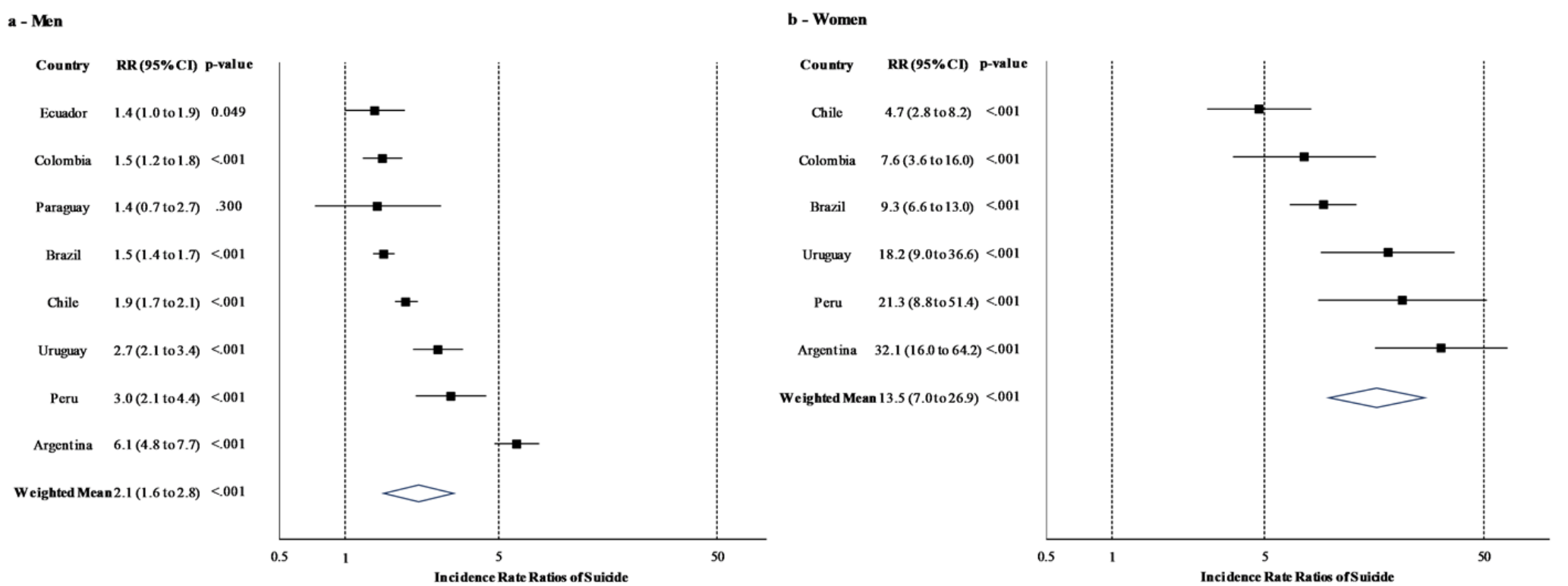

Univariate meta-regression analysis showed a significant negative association between incidence of suicide and overcrowding when male and female genders were combined $(\beta=-57.8,95 \% \mathrm{CI}=-108.5$ to $-7.1, \mathrm{p}=.033, \mathrm{n}=7$; Figure 2). We found no significant associations between the incidence rates of prison suicide and any of the other variables (Table 2). 
Fig. 2 Rates of annual suicides per 100000 person years of imprisonment compared with prison occupancy rates of 7 South American countries

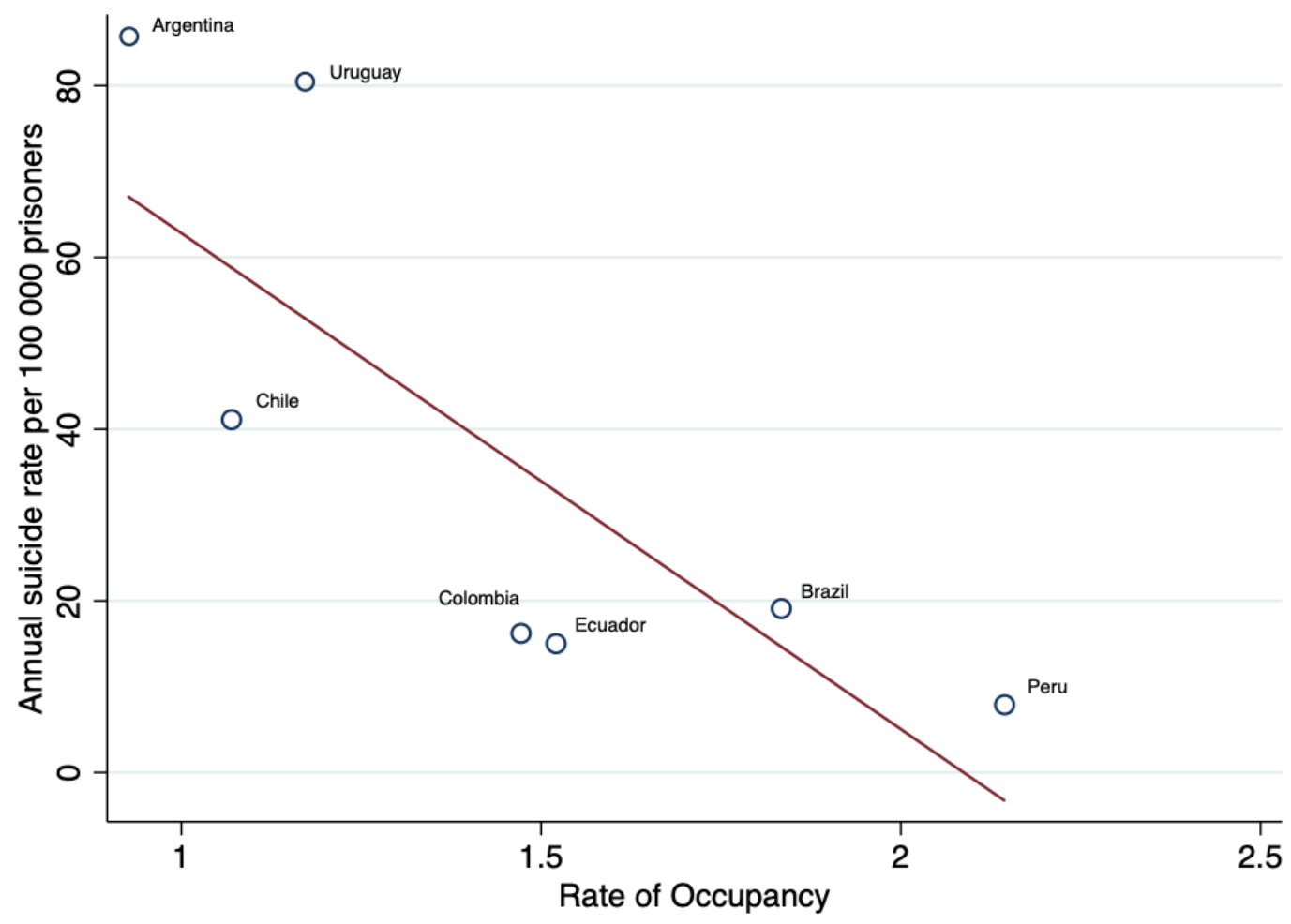

Furthermore, prison suicide rates showed a non-significant association with suicide rates in the general population when male and female genders were combined $(\beta=3.81, \mathrm{p}=.05, \mathrm{n}=8)$. For men, there was a significant positive association between suicide incidence in prison and suicide incidence in the general populations $(\beta=2.55, \mathrm{p}=.036, \mathrm{n}=8)$. We found a non-significant increase over time in Uruguay $(\beta=.57, \mathrm{p}=.05$; Supplementary Table 6$)$. No time trends were seen for the other countries (Supplementary Table 6).

Table 2 Meta-regression analyses with suicide rates of prison populations as dependent variable and gender, suicide rate in the general population, incarceration rates, rates of occupancy and year as independent variables in eight South American countries between 2000 and 2017

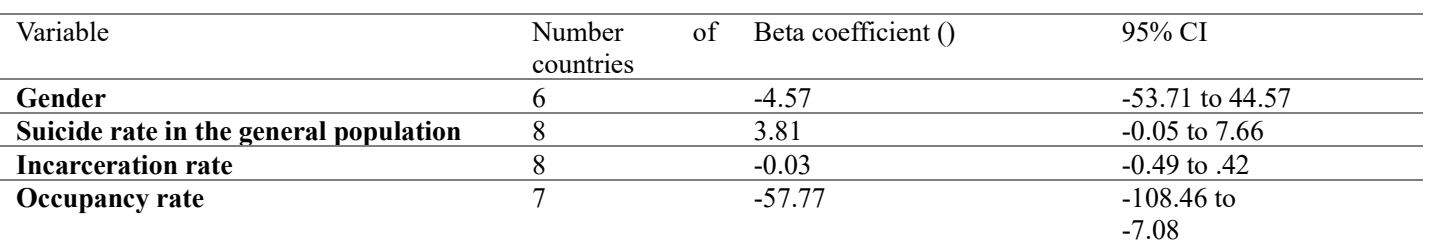


There was variability between countries regarding data completeness (Table 3). Countries that only provided data from specific types of custodial institutions (Argentina, Bolivia) showed higher suicide rates compared with countries that provided suicide information for all national prison facilities $(\mathrm{p}=.035)$. The definition of suicide incidence was not significantly associated with incidence rates.

Table 3 Data completeness and definitions of suicide deaths in prison of 10 South American countries

\begin{tabular}{|c|c|c|c|c|c|c|c|c|}
\hline & $\begin{array}{l}\text { Data } \\
\text { cover } \\
\text { more } \\
\text { than } 10 \\
\text { years? }\end{array}$ & $\begin{array}{l}\text { Data cover } \\
\text { all public } \\
\text { prisons in } \\
\text { the } \\
\text { country? }\end{array}$ & $\begin{array}{l}\text { All deaths in } \\
\text { prison } \\
\text { classified? }\end{array}$ & $\begin{array}{l}\text { Necessary to } \\
\text { prove } \\
\text { intent? }\end{array}$ & $\begin{array}{l}\text { Necessary to } \\
\text { investigate the } \\
\text { circumstances of } \\
\text { accidental deaths? }\end{array}$ & $\begin{array}{l}\text { Includes } \\
\text { suicides in } \\
\text { prison } \\
\text { hospitals? }\end{array}$ & $\begin{array}{l}\text { Includes } \\
\text { suicides in } \\
\text { community } \\
\text { hospitals? }\end{array}$ & $\begin{array}{l}\text { Includes suicides } \\
\text { outside of prison } \\
\text { (e.g. during leave } \\
\text { or house arrest)? }\end{array}$ \\
\hline Argentina & No & No & Yes & Yes & Yes & Yes & Yes & No \\
\hline Bolivia & Yes & No & Yes & No & Yes & No & Yes & No \\
\hline Brazil & No & Yes & No & - & - & - & - & - \\
\hline Chile & Yes & Yes & Yes & No & No & Yes & Yes & No \\
\hline Colombia & No & - & - & - & - & - & - & - \\
\hline Ecuador & Yes & Yes & Yes & Yes & Yes & Yes & Yes & Yes \\
\hline Guyana & Yes & Yes & Yes & Yes & Yes & Yes & Yes & No \\
\hline Paraguay & No & Yes & No & No & No & No & No & No \\
\hline Peru & No & Yes & No & Yes & Yes & Yes & No & No \\
\hline Uruguay & Yes & Yes & Yes & Yes & Yes & NA & NA & NA \\
\hline
\end{tabular}

\section{Discussion}

\section{Main Findings}

This study provides an overview of 1324 suicides of prisoners in 10 South American countries between 2000 and 2017, and investigated associations with a range of prison-related factors and the population suicide rate. Prison suicide rates showed high heterogeneity between countries ranging from 8 suicides per 100000 person years in Peru to 86 per 100 000 in Argentina. Despite this, suicide rates of prisoners exceeded those of general populations in all 10 countries when both genders were combined. We found that, compared with the general population, female prisoners showed significantly higher rate ratios than male prisoners, and suicide rates correlated negatively with prison occupancy rates. In men, suicide rates of prison populations correlated positively with country- and age-matched rates in the general population. 


\section{Strengths and limitations}

Strengths of this study include assessing associations with different variables spanning the criminal justice systems, general populations and trends over time. We studied 10 of the 12 sovereign nations in South America, among those the most populous countries Brazil, Colombia, and Argentina. In most countries, the information on prison suicide was not publicly available and had to be obtained directly from local prison administrations and separate governmental institutions dedicated to collect data on the health of prisoners (Argentina, Bolivia, Uruguay). All data originated from primary sources. To our knowledge, no other sources for this data exist in the respective countries.

The study also has several limitations. We did not obtain data from Suriname and Venezuela and do not know whether the data were available to local prison administrations, since all intents to collaborate directly with prison administrations or with researchers from those two countries were not unsuccessful. There was limited availability of data points over time in several of the countries. In some countries, data were collected in intervals, not continuously. There was limited availability of possibly associated variables relating to individual level risk factors and criminal justice factors. In some countries not all deaths were classified (Table 3). This may lead to inaccurate death counts for any cause. There was no clear indication that prison administrations had any incentives in classifying more or less deaths as suicide compared to other causes of death. Several countries had separate counts for deaths of unknown cause and homicide counts were higher than suicide counts, where these data were available. However, for instance in Argentina, the data source was a public institution independent from the federal prison administration. This institution raised doubts as to whether all deaths by hangings should immediately be classified as suicide and it pronounced concern as for the methods the prison administration used to determine the available housing spaces, possibly underestimating rates of occupancy.

\section{Interpretation and comparison against the literature}

South American prison suicide rates were mostly lower than those in Western European high-income countries, but similar to those in North America, Australia, and South Africa [1,4]. We reported a fourfold suicide rate ratio when male and female genders were combined comparing prisoner to the general population rates. To our knowledge, this is the first overall estimate for South America and also for a group of middle-income countries. The reported higher rate ratio for women suggests that prevention policies should give special attention to female prisoners, although it

must be noted that suicides among women in prison are rare events. Research on a possible relationship between overcrowding and suicide has been inconclusive: Two studies conducted in high-income countries found a positive association between overcrowding and suicide [2,27], while one found a negative association [28], and three no 11 
association $[1,23,29]$ between the two variables. The current investigation showed a negative association between overcrowding and suicide of prisoners. Also, occupancy rates were on average much higher than in high-income countries [1]. A possible explanation proposed in previous literature for a negative association, has been that overcrowding prevents the placement of prisoners in single cells, which has been repeatedly described as risk factor, while also acting as a form of forced peer supervision among prisoners. However, the measure of association found in this study does not allow for the inference of a causal relationship between the two variables. To assess prison suicide rates and overcrowding at the level of single institutions rather than a national level, as well as controlling for further ecological factors could provide more information about the links between the prison environment and suicide rates. Our study also showed an association between suicides in male prison and general populations. This has not been reported in previous research. It may indicate consistency of measures between prison and general populations within countries. It could also mean the importation of risk factors from the general to the prison population. The association between rates of incarceration and prison suicide rates that has been reported for high-income economies $[1,2,23,30]$ was not replicated in this group of South American countries. Examining these variables in other middle-income regions could further clarify a possible relationship. Other factors that might be relevant include homicide rates in prisons, rates of self-harm, and the amount of meaningful daytime activity in custody, number of remand/sentenced prisoners, which were not available. We recommend the periodic collection and publication of these data, in order to further investigate possible risk factors for suicide, and target and monitor prevention, as this may have been instrumental to address prison suicide in other countries [31]. The high heterogeneity between countries may partly be explained by varying definitions of suicide deaths and methods used to collect those data. In Bolivia, the data originated from a single institution, in which the control of prison guards was usually limited to the perimeter of the institution, while internal control was exerted by imprisoned individuals and gangs. Violent behaviours were associated with higher suicide risk in criminal justice populations [16,32]. In Argentina, data originated from the federal prison system, which held prisoners of specific criminal characteristics. This may explain that the two countries had higher prison suicide rates. With regard to the definitions of suicide, we hypothesized that proving intent as part of suicide investigation would lead to stricter definitions and hence lower rates, but this did not appear to be case.

\section{Implications for research and health policy}

With regards to the socioeconomic, cultural and infrastructural differences between South-America and the highincome countries, future research in the region may want to assess further individual- and prison-level variables, such as psychiatric morbidity, psychiatric medication, non-lethal self-harm, being on remand, lack of meaningful activities, 
bullying, social isolation, and homicide rates within prison. Adequate suicide risk screening methods should be developed and tested, as current tools still result in high numbers of false positives and false negatives [9].

Prison administrations in South America should regularly publish data on their prison populations with special regards to the health of prisoners and unify data collection methods and definitions to assist comparisons and research. For instance, the creation of a joint and independent database for the collection of prison data across the South-American region, as is the Council of Europe Annual Penal Statistics for 47 European states, could create the basis for comparable data collection methods and definitions to assist research and the design of future prison and public health policies. Prison populations are at substantially higher risk of suicide than general populations in South America. The investigated countries require collaboration of health, criminal justice, and third sector agencies to address the development of suicide prevention. In particular, scaling up adequate access to mental health screening and treatment for prison populations may be one way forward to reduce excess suicide mortality in South American prisons. As recommended in WHO guidelines and previous research conducted in high income countries [9,33], prisoners should first be screened at reception for suicide risk and psychiatric disorders, as the early period of custody has been the one with the highest risk of suicide. Prisoners who suffer from severe psychiatric illness should be diverted, for instance to secure hospitals or onto treatment orders. Healthcare services in prison should be equivalent to those available to the general population; the provision of healthcare, including mental health services, should be managed by public health systems, so that providers can act in the best interest of the patients and maintain independence from the justice system.

\section{Compliance with ethical Standards}

Ethical approval was obtained from the Universidad de Antioquia (Colombia). The authors assert that all procedures contributing to this work comply with the Helsinki Declaration of 1975, as revised in 2008.

\section{Conflict of Interest}

The authors declare that they have no conflict of interest.

\section{Author Contributions}

The study was designed by Seena Fazel and Adrian P. Mundt. Francesco D. Fritz conducted the literature search. Francesco D. Fritz, Andres Benavides Salcedo, Paulette Henry, Guillermo Rivera Arroyo, Julio Torales, Natalia 
Trujillo Orrego, Freddy Vasquez and Adrian P. Mundt contributed to the data collection. Analyses were conducted by Francesco D. Fritz, Seena Fazel and Adrian P. Mundt. The manuscript was drafted by Francesco D. Fritz and Adrian P. Mundt. Francesco D. Fritz, Seena Fazel, Andres Benavides Salcedo, Paulette Henry, Guillermo Rivera Arroyo, Julio Torales, Natalia Trujillo Orrego, Freddy Vasquez and Adrian P. Mundt critically revised the manuscript and approved of the final version.

\section{Acknowledgements}

The authors wish to acknowledge and thank José Pedro Rossi and Santiago Sosa Barón of the Parliamentary Commission for the Prison System of the Uruguayan Parliament (Montevideo, Uruguay), and Ramiro Gual and Liliana Martinez of the Procuración Penitenciaria de la Nación (Buenos Aires, Argentina). This work was supported the Wellcome Trust [grant number 202836/Z/16/Z] and the Comisión Nacional de Investigación Cientifica y Tecnologica, Ministry of Education, Republic of Chile [grant FONDECYT Regular number 1190613].

\section{References}

1. Fazel S, Ramesh T, Hawton K (2017) Suicide in prisons: an international study of prevalence and contributory factors. Lancet Psychiatry 4 (12):946-952. doi:10.1016/S2215-0366(17)30430-3

2. Rabe K (2012) Prison structure, inmate mortality and suicide risk in Europe. Int J Law Psychiatry 35 (3):222-230. doi:10.1016/j.ijlp.2012.02.012

3. Folino JO, Marchiano S, Sanchez Wilde A (2003) [Suicide in convicts in Buenos Aires Province]. Vertex 14 (54):286-291

4. Bantjes J, Swartz L, Niewoudt P (2017) Human rights and mental health in post-apartheid South Africa: lessons from health care professionals working with suicidal inmates in the prison system. BMC Int Health Hum Rights 17 (1):29. doi:10.1186/s12914-017-0136-0

5. Almanzar S, Katz CL, Harry B (2015) Treatment of mentally ill offenders in nine developing Latin American countries. J Am Acad Psychiatry Law 43 (3):340-349

6. Beyen TK, Dadi AF, Dachew BA, Muluneh NY, Bisetegn TA (2017) More than eight in every nineteen inmates were living with depression at prisons of Northwest Amhara Regional State, Ethiopia, a cross sectional study design. BMC Psychiatry 17 (1):31. doi:10.1186/s12888-016-1179-9 
7. Joshua IA, Dangata YY, Audu O, Nmadu AG, Omole NV (2014) Human Rights and Nigerian Prisoners--Are Prisoners Not Humans? Med Law 33 (4):11-20

8. Shrestha G, Yadav DK, Sapkota N, Baral D, Yadav BK, Chakravartty A, Pokharel PK (2017) Depression among inmates in a regional prison of eastern Nepal: a cross-sectional study. BMC Psychiatry 17 (1):348. doi:10.1186/s12888-017-1514-9

9. Fazel S, Hayes AJ, Bartellas K, Clerici M, Trestman R (2016) Mental health of prisoners: prevalence, adverse outcomes, and interventions. Lancet Psychiatry 3 (9):871-881. doi:10.1016/S2215-0366(16)30142-0

10. Fazel S, Seewald K (2012) Severe mental illness in 33,588 prisoners worldwide: systematic review and metaregression analysis. Br J Psychiatry 200 (5):364-373. doi:10.1192/bjp.bp.111.096370

11. Andreoli SB, Dos Santos MM, Quintana MI, Ribeiro WS, Blay SL, Taborda JG, de Jesus Mari J (2014)

Prevalence of mental disorders among prisoners in the state of Sao Paulo, Brazil. PloS one 9 (2):e88836. doi:10.1371/journal.pone.0088836

12. Mundt AP, Alvarado R, Fritsch R, Poblete C, Villagra C, Kastner S, Priebe S (2013) Prevalence rates of mental disorders in chilean prisons. PloS one 8 (7):e69109. doi:10.1371/journal.pone.0069109

13. Baier A, Fritsch R, Ignatyev Y, Priebe S, Mundt AP (2016) The course of major depression during imprisonment - A one year cohort study. J Affect Disord 189:207-213. doi:10.1016/j.jad.2015.09.003

14. Baranyi G, Scholl C, Fazel S, Patel V, Priebe S, Mundt AP (2019) Severe mental illness and substance use disorders in prisoners in low-income and middle-income countries: a systematic review and meta-analysis of prevalence studies. Lancet Glob Health 7 (4):e461-e471. doi:10.1016/S2214-109X(18)30539-4

15. Hawton K, Linsell L, Adeniji T, Sariaslan A, Fazel S (2014) Self-harm in prisons in England and Wales: an epidemiological study of prevalence, risk factors, clustering, and subsequent suicide. Lancet 383 (9923):1147-1154. doi:10.1016/S0140-6736(13)62118-2

16. Fruehwald S, Matschnig T, Koenig F, Bauer P, Frottier P (2004) Suicide in custody: case-control study. Br J Psychiatry 185:494-498. doi:10.1192/bjp.185.6.494

17. Fazel S, Cartwright J, Norman-Nott A, Hawton K (2008) Suicide in prisoners: a systematic review of risk factors. Nov 69 (11):1721-1731

18. Jakobowitz S, Bebbington P, McKenzie N, Iveson R, Duffield G, Kerr M, Killaspy H (2017) Assessing needs for psychiatric treatment in prisoners: 2. Met and unmet need. Soc Psychiatry Psychiatr Epidemiol 52 (2):231-240.

doi: $10.1007 / \mathrm{s} 00127-016-1313-5$

15 
19. Mundt AP, Chow WS, Arduino M, Barrionuevo H, Fritsch R, Girala N, Minoletti A, Mitkiewicz F, Rivera G, Tavares M, Priebe S (2015) Psychiatric hospital beds and prison populations in South America since 1990: does the Penrose hypothesis apply? JAMA psychiatry 72 (2):112-118. doi:10.1001/jamapsychiatry.2014.2433

20. Walmsley R (2018) World Prison Population List (twelfth edition). Institute for Criminal Policy Research. http://www.prisonstudies.org/sites/default/files/resources/downloads/wppl_12.pdf. Acces-sed 12.07.2019 21. Priebe S, Frottier P, Gaddini A, Kilian R, Lauber C, Martínez-Leal R, Munk-Jørgensen P, Walsh D, Wiersma D, Wright D (2008) Mental health care institutions in nine European countries, 2002 to 2006. Psychiatr Serv 59 (5):570573. doi:10.1176/ps.2008.59.5.570

22. Mundt AP, Frančiskovič T, Gurovich I, Heinz A, Ignatyev Y, Ismayilov F, Kalapos MP, Krasnov V, Mihai A, Mir J, Padruchny D, Potocan M, Raboch J, Taube M, Welbel M, Priebe S (2012) Changes in the provision of institutionalized mental health care in post-communist countries. PloS one 7 (6):e38490.

doi:10.1371/journal.pone.0038490

23. van Ginneken EF, Sutherland A, Molleman T (2017) An ecological analysis of prison overcrowding and suicide rates in England and Wales, 2000-2014. Int J Law Psychiatry 50:76-82. doi:10.1016/j.ijlp.2016.05.005

24. García-Guerrero J, Marco A (2012) [Overcrowding in prisons and its impact on health]. Rev Esp Sanid Penit 14 (3):106-113. doi:10.4321/S1575-06202012000300006

25. Federal Bureau of Prisons (2019) Inmate Statistics. Federal Bureau of Prisons. https://www.bop.gov/about/statistics/statistics_inmate_age.jsp. Accessed 31th August 20192019 26. House of Commons Library (2019) UK Prison Population Statistics. House of Commons Library. https://researchbriefings.parliament.uk/ResearchBriefing/Summary/SN04334. Accessed 31th August 20192019 27. Huey MP, Mcnulty TL (2005) Institutional Conditions and Prison Suicide: Conditional Effects of Deprivation and Overcrowding. The Prison Journal 85 (4):490-514. doi:10.1177/0032885505282258

28. Duthe G, Hazard A, Kensey A, Shon JL (2013) Suicide among male prisoners in France: a prospective population-based study. Forensic Sci Int 233 (1-3):273-277. doi:10.1016/j.forsciint.2013.09.014

29. Fruehwald S, Frottier P, Ritter K, Eher R, Gutierrez K (2002) Impact of overcrowding and legislational change on the incidence of suicide in custody experiences in Austria, 1967-1996. Int J Law Psychiatry 25 (2):119-128 30. Fazel S, Grann M, Kling B, Hawton K (2011) Prison suicide in 12 countries: an ecological study of 861 suicides during 2003-2007. Mar 46 (3):191-195. doi:10.1007/s00127-010-0184-4 
31. Bird SM (2008) Changes in male suicides in Scottish prisons: 10-year study. Br J Psychiatry 192 (6):446-449. doi:10.1192/bjp.bp.107.038679

32. Fazel S, Wolf A, Larsson H, Mallett S, Fanshawe TR (2019) The prediction of suicide in severe mental illness: development and validation of a clinical prediction rule (OxMIS). Transl Psychiatry 9 (1):98. doi:10.1038/s41398019-0428-3

33. Marzano L, Hawton K, Rivlin A, Smith EN, Piper M, Fazel S (2016) Prevention of Suicidal Behavior in Prisons. Crisis 37 (5):323-334. doi:10.1027/0227-5910/a000394 